\title{
Immunocytochemical Detection of Recombinant Biomphalysin on Schistosoma mansoni Sporocysts
}

David Duval ${ }^{*}$, Richard Galinier, Julien Portela, Guillaume Mitta and Benjamin Gourbal

Ecologie et Evolution des Interactions (2EI), UPVD, CNRS, UMR 5244, Perpignan, France

*For correspondence: david.duval@univ-perp.fr

[Abstract] Schistosomiasis, or bilharzia, is a tropical disease caused by worms of the genus Schistosoma which infect about 200 million people. The life cycle of the parasite requires Biomphalaria, a specific genus of freshwater snails, as intermediate. Using an interactome approach employing B. glabrata plasma and S. mansoni primary sporocyst extracts, we identified a new cytolytic protein called Biomphalysin that displays similarities to members of the $\beta$-PFT superfamily known to form channels in targeted membranes. To investigate its mechanism of action, we produced a recombinant protein flanked by an N-terminal 6 histidine tag. Then, we investigated the ability of Biomphalysin to interact with the sporocyst tegument. This optimized protocol describes an immunocytochemical procedure to detect histidine tagged recombinant protein on the sporocyst tegumental membrane.

\section{Materials and Reagents}

1. Paraformaldehyde (PAF) (Sigma-Aldrich, catalog number: 158127)

2. PBS (Sigma-Aldrich, catalog number: P4417)

3. BSA (Sigma-Aldrich, catalog number: A3803)

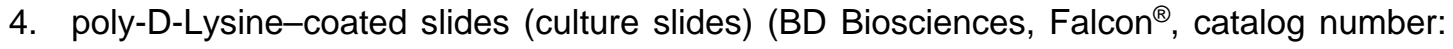
354632)

5. Mouse anti-HisG monoclonal antibody (Life Technologies, catalog number: R940-25)

6. Alexa Fluor 594 goat anti-mouse IgG (Life Technologies, catalog number: A 110005)

7. Dako fluorescent mounting medium (Dako, catalog number: S3023)

8. Primary sporocysts of S. mansoni (Brazilian strain) used for immunocytochemical experiments were obtained by transferring miracidia to Chernin's balanced salt solution (CBSS) and maintaining at $26{ }^{\circ} \mathrm{C}$ under normoxic conditions for $24 \mathrm{~h}$ (Yoshino and Laursen, 1995). Then, 100 primary sporocysts were incubated for $1 \mathrm{~h}$ with $30 \mathrm{nM}$ of recombinant Biomphalysin protein (Galinier et al., 2013). As negative control, 100 sporocysts were used without having been treated with recombinant biomphalysin. 
9. $N$ terminal His(6)-tagged biomphalysin was expressed in vitro using the Rapid Translation System (RTS 500 Wheat Germ CECF Kit) (5 PRIME, catalog number. 2402500)

10. $4 \%$ PAF (see Recipes)

11. PBS/3\% BSA (see Recipes)

12. $\mathrm{PBS} / 1 \% \mathrm{BSA}$ (see Recipes)

13. Anti- HisG antibody 1:500 (see Recipes)

14. Anti-mouse IgG 1:1,000 (see Recipes)

\section{Equipment}

1. Coverslip $24 \times 60 \mathrm{~mm}$ (VWR International, catalog number: 631-1575)

2. BD BioCoat ${ }^{\mathrm{TM}}$ Poly-D-Lysine 8-well CultureSlides (Becton, Dickinson and Company, catalog number: 354632)

3. Eppendorf centrifuge (Eppendorf , model: 5810R)

4. Swinging agitator (Fisher scientific, model: 10758995)

5. Fluorescence confocal laser-scanning microscope (ZEISS, model: LSM 700)

\section{Procedure}

1. Collect $\mathbf{1 0 0}$ sporocysts and transfer to culture slide coated with poly-D-Lysine.

2. Centrifuge culture slide at $800 \times g$ for $2 \mathrm{~min}$.

3. Aspirate supernatant and fix sporocysts with $200 \mu \mathrm{l} 4 \%$ PAF during 1 hour at room temperature.

4. Centrifuge culture slide at $800 \times g$ for 2 min and aspirate supernatant.

5. Wash twice with $200 \mu \mathrm{l}$ PBS and repeat step 4.

6. Add $200 \mu \mathrm{l} \mathrm{PBS} / 3 \% \mathrm{BSA}$ and incubate for $2 \mathrm{~h}$ at room temperature without agitation.

7. Centrifuge culture slide at $800 \times g$ for $2 \mathrm{~min}$ and aspirate supernatant.

8. Add $200 \mu \mathrm{l}$ anti-His antibody diluted at 1:500 in PBS and incubate $1.5 \mathrm{~h}$ at room temperature with a shaking speed of approximately 12 oscillations per minute.

9. Wash three times with $200 \mu \mathrm{l}$ PBS during 5 min with a shaking speed of 12 oscillations per minute and between wash, centrifuge culture slide.

10. Incubate sporocysts with $200 \mu \mathrm{l}$ Alexa Flour 594-conjugated anti-mouse IgG diluted 1:1,000 in PBS/1\% BSA for $45 \mathrm{~min}$ at room temperature and protect slides from light with a shaking speed of 12 oscillations per minute.

11. Repeat step 9.

12. Place 2 drops of Dako fluorescent mounting medium on slide and cover with a coverslip. 
13. Leave mounted slide overnight at $4{ }^{\circ} \mathrm{C}$ and protect slides from light before observation.

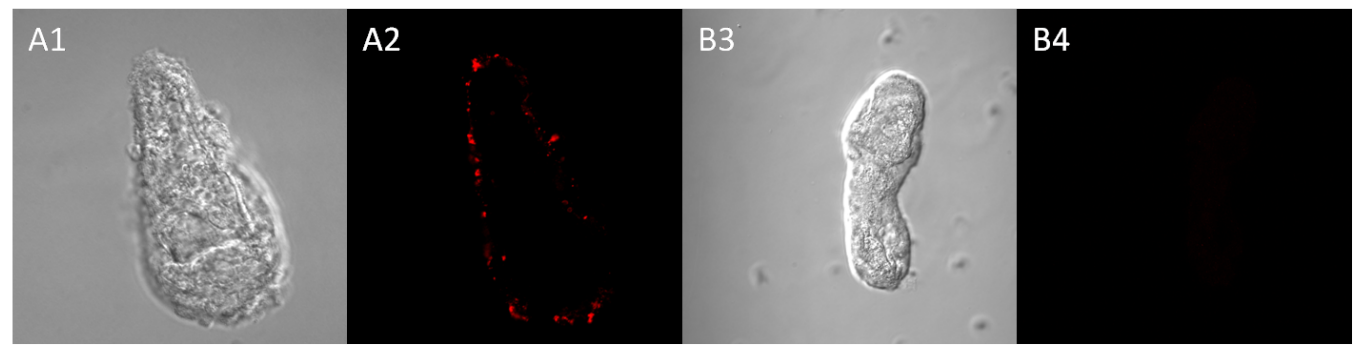

Figure 1. Immunolocalization of recombinant Biomphalysin on $S$. mansoni sporocyst. Sporocysts were treated or not with recombinant Biomphalysin (A : positive and $B$; negative control, respectively) and immunostained using anti-His primary lgG and Alexa Fluor 594-conjugated secondary antibodies. Images 1 and 3 were taken under Nomarski light microscopy; images 2 and 4 under using a fluorescence confocal laserscanning microscope (Zeiss LSM 700).

\section{$\underline{\text { Recipes }}$}

1. $4 \% \mathrm{PAF}$

Dissolve $4 \mathrm{mg} \mathrm{PAF}$ in $100 \mathrm{ml}$ PBS (heat to $60^{\circ} \mathrm{C}$ for $1 \mathrm{~h}$ with stirring)

The cooled solution can be filtered and stored at $-20^{\circ} \mathrm{C}$

2. $\mathrm{PBS} / 3 \% \mathrm{BSA}$

$0.3 \mathrm{mg}$ BSA in $10 \mathrm{ml}$ PBS

3. $\mathrm{PBS} / 1 \% \mathrm{BSA}$

$0.1 \mathrm{mg}$ BSA in $10 \mathrm{ml}$ PBS

4. Anti- His antibody 1:500

$0.5 \mu \mathrm{l}$ anti-his antibody in $250 \mu \mathrm{l}$ PBS only

5. Anti-mouse IgG 1:1,000

$0.5 \mu \mathrm{l}$ anti-mouse IgG in $250 \mu \mathrm{lPBS} / 1 \% \mathrm{BSA}$

\section{Acknowledgments}

We thank Anne Rognon and Nathalie Arancibia for technical assistance. We thank all team members for their advice and fruitful discussions. This work was supported by funds from the Centre National de la Recherche (CNRS) and the Université de Perpignan Via Domitia (UPVD), and by a grant from the ANR (25390 Schistophepigen). The funders had no role in study design, data collection and analysis, decision to publish, or preparation of the manuscript. 


\section{References}

1. Galinier, R., Portela, J., Mone, Y., Allienne, J. F., Henri, H., Delbecq, S., Mitta, G., Gourbal, B. and Duval, D. (2013). Biomphalysin, a new beta pore-forming toxin involved in Biomphalaria glabrata immune defense against Schistosoma mansoni. PLoS Pathog 9(3): e1003216.

2. Yoshino, T. P. and Laursen, J. R. (1995). Production of Schistosoma mansoni daughter sporocysts from mother sporocysts maintained in synxenic culture with Biomphalaria glabrata embryonic (Bge) cells. J Parasitol 81(5): 714-722. 